\title{
The New Approach of the Impedance Calculation Method of Fault Current Analysis in the AT Feeding Method of the Electric Railway
}

\author{
No-Geon Jung* and Ki-Sik Lee ${ }^{\dagger}$
}

\begin{abstract}
The cause of failure in the AT feeding method of the electric railway is divided into ground, short of feeding circuit and faults on the inside of the substation. Because the fault current is high, the real-time current is detected and the failure promptly has to be removed.

In this paper, short-circuit current is analyzed by numerical analysis and simulation is made for the correct operation of the protective relay and the impedance calculation method has been proposed for simple and accurate calculation of the short-circuit current. Also, In order to confirm the validity of the proposed calculation method, the simulation error rate was analyzed compared with the conventional numerical methods.
\end{abstract}

Keywords: AC electric railway, Fault current, Short-circuit, Numerical analysis

\section{Introduction}

The electrification of the railroad is continuously accomplished with the opening of the demands of the domestic high speed railway and need for a qualityenhanced means of railroad transportation is increasing dependent on changing transportation demands. In addition, the reliance on electrical power is gradually rising in the railroad field of industry [1-2]. Therefore, the stable supply of electricity power applied to the electric railway vehicle and claims about improvement of power quality are suddenly increasing and the importance of the protective relay acting in the stability maintenance of the power system is increasing. The cause of the failure in the $\mathrm{AC}$ electric railway power system is divided into Ground, Short of feeding circuit and faults on the inside of the substation[3-4], because the fault current is high, the realtime current is detected and the failure promptly has to be removed. because of high speed of the railway vehicle powered by the electrical energy and the increase of power load and regenerative power available from the electric railway vehicle, there is not a big difference between fault current and load current. The high performance protection system is necessary in order to prevent malfunction to the protective relay due to the load current. In order to implement the high performance protection system, detailed modelling about the element of the power feeding system has to be preceded. The foreign product is mostly applied to the $\mathrm{AC}$ protective relay for the feed system that is the constituent of AC feeding system that is being applied domestically. High cost of the protective relay construction and maintenance is occurred with the independent technical

$\dagger$ Corresponding Author: Dept. of Electrical and Electronics Engineering, Dankook University, Korea. (kisiklee@dankook.ac.kr)

* Dept. of Transportation System Engineering Korea national

University of Transportation, Korea. (bossjng@ut.ac.kr)

Received: September 14, 2015; Accepted: February 25, 2016 absence of the protective relay. Protection function of every foreign product is already equipped, standardized protection for the $\mathrm{AC}$ feeder system is difficult.

In this paper, the short-circuit current is analyzed by numerical analysis and simulation for the correct operation of the protective relay and the formula has been proposed for simple and accurate calculation of the short-circuit current.

Also, in order to confirm the validity of the proposed formula, the simulation error rate was analyzed compared with the conventional numerical methods. And the formula applying the AT leakage impedance was derived and compared with simulation.

\section{Impedance Calculation and Simulation}

The AT feeding method is widely used, and for power, has good characteristics for high power long-distance feeding and induced obstacle because of the recent surge in load current. AT feeding method is the system for connecting the neutral point of the transformer winding on a rail at about $10[\mathrm{~km}]$ intervals along the track.

In this paper, a short-circuit current was calculated through a short-circuit impedance derived in accordance with the circuit configuration for fault current analysis.

\subsection{AC AT feeder system}

Typically, the feed circuit applied in Korea for supporting a train which uses electricity as the energy source is shown as in Fig. 1.

This circuit consists of substation, sectioning post which uses closing and opening for division and extension of feeder section, sub sectioning post for restriction from power failure or blackout when working and accident, auto 


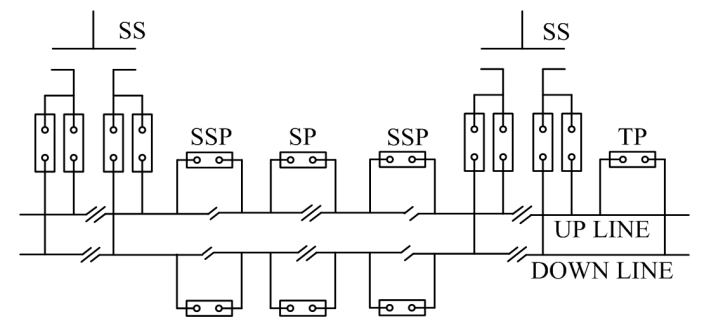

Fig. 1. Configuration diagram of AC feeder circuit

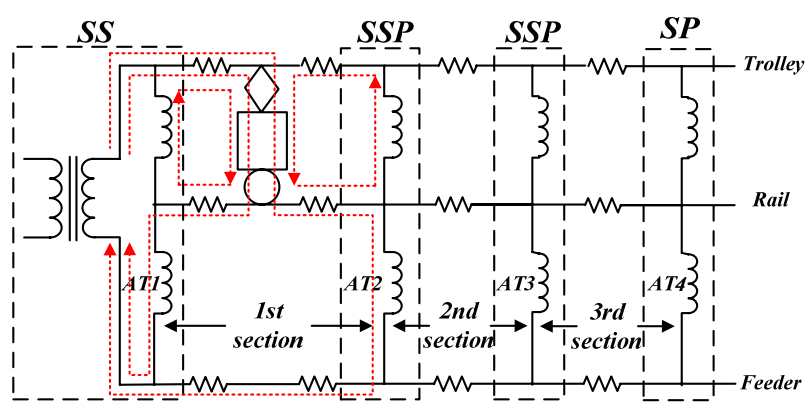

Fig. 2. AC Electric railway of AT feeder method

transformer post for voltage drop compensation of overhead trolley wire on catenary terminal and reduction of inductive disturbance [5-7].

Also, TP(Tie-Post) is installed and operated as arc measures for cross over road for short railroad terminal.

Fig. 2 is equivalent circuit of Fig. 1 and shows AT method of electric supply which most of Korea has been using. The AT is installed on the trolley and feeder, and the neutral point is installed on the rail. This method has both ends of ATs connected to trolley and feeder.

Thus, trolley has higher electric potential than rail and feeder has lower electric potential than rail and earth.

AT applies $55[\mathrm{kV}]$ between trolley and feeder based on scott transformer secondary-side and $27.5[\mathrm{kV}]$ between trolley and rail since neutral point is connected to the trolley and rail.

\subsection{Conventional calculation method}

Fig. 3 shows power supply circuit impedance characteristic between trolley, rail and feeder, as shown in Fig. 2. There are T-R short circuit, F-R short circuit, T-F short circuit in $\mathrm{AC}$ electric railway AT feeding method. Impedance increases with distance increase of fault location from traction substation (SS). However, impedance decreases if it gets closer to the specific location AT such as sectioning post (SP), then sub sectioning post (SSP) is installed [8].

Conversely, in the first section of Fig. 3, when AT interval distance is represented by $D$, the distance to the T$\mathrm{R}$ short circuit point at the substation installed AT is represented by $x$, circuit excluding the load of the vehicle is the same as Fig. 4. Short circuit impedance as a short circuit occurs in first section impedance is represented by $Z$ and Short circuit impedance, as a short circuit, occurs in a

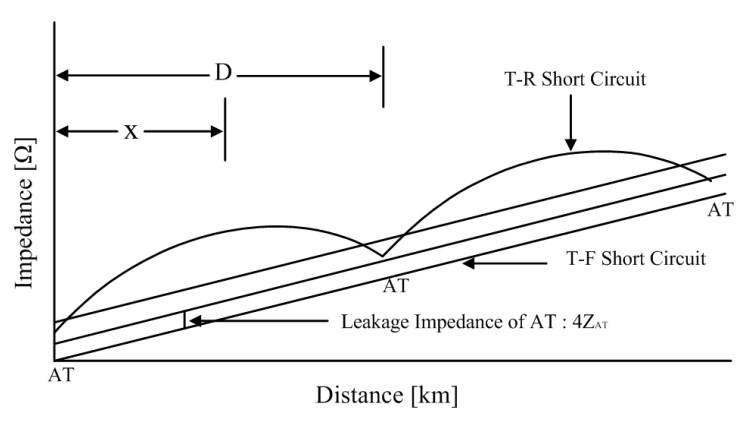

Fig. 3. Impedance characteristic of AT feeder method

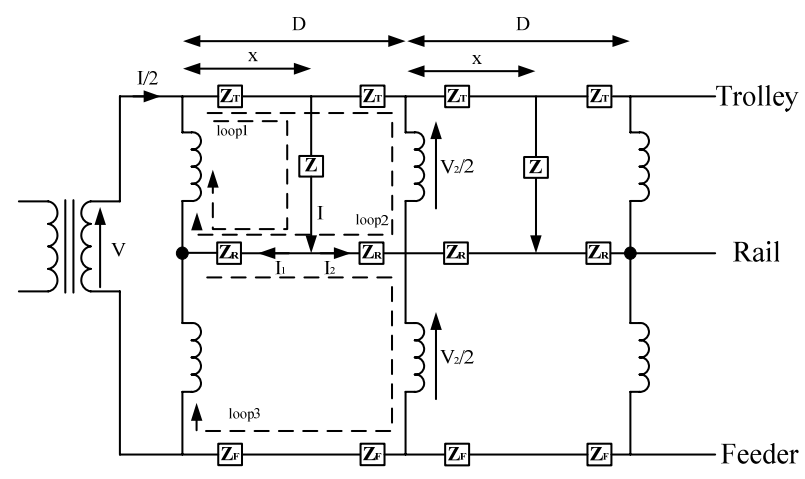

Fig. 4. Single-line simplified equivalent circuit

second section represented by $Z^{\prime}$ [9].

Eqs. (1) (3) of equivalent circuit of Fig. 4 are satisfied by the Kirchhoff's law in the loop 1 3 single-line simplified equivalent circuit of Fig. 4[10].

$$
\begin{gathered}
\frac{V}{2}=Z\left(I_{1}+I_{2}\right)+Z_{T} x\left(\frac{2 I_{1}+I_{2}}{2}\right)+Z_{R} x I_{1} \\
\frac{V}{2}-\frac{V_{2}}{2}=Z_{T} x\left(\frac{2 I_{1}+I_{2}}{2}\right)-Z_{T}(D-x) \frac{I_{2}}{2}+Z_{R} x I_{1} \\
\quad-Z_{R} x I_{1}-Z_{R}(D-x) I_{2} \\
\frac{V}{2}-\frac{V_{2}}{2}=\frac{Z_{F} D I_{2}}{2}-Z_{R} x I_{1}+Z_{R}(D-x) I_{2}
\end{gathered}
$$

$I_{1}, I_{2}$ can be derived from equations (1) (3). And it is possible to determine the line impedance of the case of T-R short circuit at a distance $x$ through following equation.

$$
\begin{gathered}
Z_{A L}=\frac{2 V}{\left(I_{1}+I_{2}\right)} \\
Z_{A L}=4 Z+\frac{4 D x\left(Z_{F} Z_{T}+Z_{R} Z_{F}+Z_{T} Z_{R}\right)}{4 Z_{R} D+Z_{F} D+Z_{T} D} \\
+\frac{4(D-x) x\left(Z_{T}+2 Z_{R}\right)^{2}}{4 Z_{R} D+Z_{F} D+Z_{T} D}
\end{gathered}
$$

In the second section, the addition of $\frac{4 D H}{G}$ in Eq. (5) is the same as Eq. (6). 


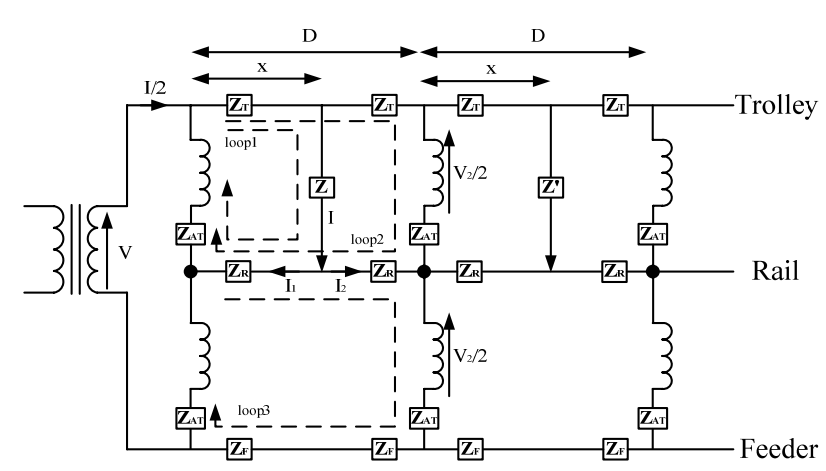

Fig. 5. Simple equivalent circuit in $2^{\text {nd }}$ section

$$
\begin{aligned}
Z_{A L}= & 4 Z+\frac{4 D x\left(Z_{F} Z_{T}+Z_{R} Z_{F}+Z_{T} Z_{R}\right)}{4 Z_{R} D+Z_{F} D+Z_{T} D} \\
& +\frac{4(D-x) x\left(Z_{T}+2 Z_{R}\right)^{2}}{4 Z_{R} D+Z_{F} D+Z_{T} D}+\frac{4 D H}{G}
\end{aligned}
$$

where, $G=Z_{T}+Z_{F}+4 Z_{R}, \quad H=Z_{T} Z_{F}+Z_{T} Z_{R}+Z_{F} Z_{R}$

\subsection{Proposed calculation method}

The conventional formula does not include the value of AT transformer. But the proposed method is calculated by the conventional method in addition to AT leakage reactance in section 1 . but in this paper, a new calculation method is proposed for a simple and fast calculation in section 2 3

Eqs. (7) (9) of equivalent circuit of Fig. 5 are satisfied by the Kirchhoff's law in the loop 1 3 single-line simplified equivalent circuit of Fig. 5.

$$
\begin{gathered}
\frac{V}{2}=Z\left(I_{1}+I_{2}\right)+Z_{T} x\left(\frac{2 I_{1}+I_{2}}{2}\right)+Z_{R} x I_{1}+\frac{Z_{A T} I_{1}}{2} \\
\frac{V}{2}-\frac{V_{2}}{2}=Z_{T} x\left(\frac{2 I_{1}+I_{2}}{2}\right)-Z_{T}(D-x) \frac{I_{2}}{2}+Z_{R} x I_{1} \\
\quad-Z_{R} x I_{1}-Z_{R}(D-x) I_{2}-\frac{Z_{A T}\left(I_{1}-I_{2}\right)}{2} \\
\frac{V}{2}-\frac{V_{2}}{2}=\frac{Z_{F} D I_{2}}{2}-Z_{R} x I_{1}+Z_{R}(D-x) I_{2} \\
-\frac{Z_{A T}\left(I_{1}-I_{2}\right)}{2}
\end{gathered}
$$

$I_{1}, I_{2}$ can be derived from equations (7) (9). And it is possible to determine the line impedance of the case of T-R short circuit at a distance $x$ through following equation.

$$
\begin{aligned}
Z_{A L}= & 4 Z+\frac{4 D x\left(Z_{F} Z_{T}+Z_{R} Z_{F}+Z_{T} Z_{R}\right)}{4 Z_{R} D+Z_{F} D+Z_{T} D} \\
& +\frac{4(D-x) x\left(Z_{T}+2 Z_{R}\right)^{2}}{4 Z_{R} D+Z_{F} D+Z_{T} D} \\
& +\frac{\left(Z_{F} D+4 Z_{R}(D-x)-Z_{T}(2 x-D)\right) 2 Z_{A T}}{4 Z_{R} D+Z_{F} D+Z_{T} D}
\end{aligned}
$$

Table 1. Catenary Data for fault impedance calculation

\begin{tabular}{c|c|c}
\hline \multicolumn{2}{c|}{ Type } & Data \\
\hline \multirow{2}{*}{$\begin{array}{c}\text { Self impedance } \\
{[\Omega / \mathrm{km}]}\end{array}$} & Trolley & $0.1960+\mathrm{j} 0.7353$ \\
\cline { 2 - 3 } & Rail & $0.1851+\mathrm{j} 0.6219$ \\
\cline { 2 - 3 } & Feeder & $0.1782+\mathrm{j} 0.8672$ \\
\hline \multicolumn{2}{c}{ Scott transformer secondary-side voltage } & $55[\mathrm{kV}]$ \\
\hline \multicolumn{2}{c}{ Auto-transformer secondary-side voltage } & $27.5[\mathrm{kV}]$ \\
\hline $\begin{array}{c}\text { Auto-transformer leakage } \\
\text { reactance }\end{array}$ & Ideal & $0.033 \mathrm{j}[\Omega] / 10[\mathrm{MVA}]$ \\
\cline { 2 - 3 } & Real & $0.449 \mathrm{j}[\Omega] / 10[\mathrm{MVA}]$ \\
\hline
\end{tabular}

In the second section, the addition of $\left(Z_{T}+Z_{F}\right) D$ in Eq. (10) is the same as Eq. (11).

$$
\begin{aligned}
Z_{A L}= & 4 Z+\frac{4 D x\left(Z_{F} Z_{T}+Z_{R} Z_{F}+Z_{T} Z_{R}\right)}{4 Z_{R} D+Z_{F} D+Z_{T} D} \\
& +\frac{4(D-x) x\left(Z_{T}+2 Z_{R}\right)^{2}}{4 Z_{R} D+Z_{F} D+Z_{T} D} \\
& +\frac{\left(Z_{F} D+4 Z_{R}(D-x)-Z_{T}(2 x-D)\right) 2 Z_{A T}}{4 Z_{R} D+Z_{F} D+Z_{T} D} \\
& +\left(Z_{T}+Z_{F}\right) D
\end{aligned}
$$

where, $Z_{T}$ is catenary impedance $[\Omega / \mathrm{km}], Z_{R}$ is rail impedance $[\Omega / \mathrm{km}], Z_{F}$ is feeder line impedance $[\Omega / \mathrm{km}]$, $Z$ is impedance of short point $[\Omega], Z_{A L}$ is line impedance of T-R short, $D$ is distance between AT[km], Distance to the short circuit point at AT $[\mathrm{km}], Z_{A T}$ is leakage reactance of auto transformer[ $[\Omega]$

Similarly, each time a section is increased, $\left(Z_{T}+Z_{F}\right) D$ is added.

\subsection{Impedance for the fault current numerical calculation}

When an accident, such as a short circuit and ground fault occurs, EMTDC/PSACD was used to analyze the fault current. A short-circuit accident in a section of 1 20 $[\mathrm{km}]$, has been simulated at intervals of $1[\mathrm{~km}]$.

In order to calculate the fault point impedance, applied catenary impedance is shown in Table 1 as the data of the real system between the Wonju Gangneung.

Table 2 shows the calculated impedance values using the conventional numerical calculation of the impedance. The short-circuit impedance of $1[\mathrm{~km}]$ is 5.2499 [A], which was the largest current. And it was confirmed that if the distance increases and short-circuit impedance increases.

\subsection{Simulation}

Simulation was modelled with each one of the autotransformer of SP, SSP from scott transformer secondary and was modelled to be powered up to $27.5[\mathrm{kV}]$. The catenary was modelled in detail.

Fig. 6 is configured in the catenary modelling, using PSCAD / EMTDC to apply the resistance and reactance components o f trolley, rail and feeder and it is also possible to short-circuit simulation. 
Table2. Data of short-circuit Impedance according to distance

\begin{tabular}{|c|c|c|c|}
\hline \multirow{3}{*}{$\begin{array}{l}\text { Distance } \\
{[\mathrm{km}]}\end{array}$} & \multicolumn{3}{|c|}{ Short-circuit Impedance $[\Omega]$} \\
\hline & \multirow{2}{*}{$\begin{array}{l}\text { Conventional } \\
\text { equation }\end{array}$} & \multicolumn{2}{|c|}{ proposed equation } \\
\hline & & $0.033 \mathrm{j}$ & $0.45 \mathrm{j}$ \\
\hline 1 & 5.2499 & 6.8262 & 7.0279 \\
\hline 2 & 9.6893 & 11.0912 & 11.2062 \\
\hline 3 & 13.3292 & 14.5604 & 14.6510 \\
\hline 4 & 16.1698 & 17.2312 & 17.3556 \\
\hline 5 & 18.211 & 19.1032 & 19.3186 \\
\hline 6 & 19.453 & 20.1761 & 20.5454 \\
\hline 7 & 19.896 & 20.4499 & 21.0325 \\
\hline 8 & 19.5402 & 19.925 & 20.7782 \\
\hline 9 & 18.3862 & 18.6016 & 19.7913 \\
\hline 10 & 16.4352 & 16.4807 & 18.0683 \\
\hline 11 & 21.6712 & 23.2817 & 22.7273 \\
\hline 12 & 26.1094 & 27.547 & 27.0005 \\
\hline 13 & 29.7491 & 31.0152 & 30.5216 \\
\hline 14 & 32.5898 & 33.6852 & 33.2930 \\
\hline 15 & 34.6316 & 35.5568 & 35.3243 \\
\hline 16 & 35.8745 & 36.6298 & 36.5935 \\
\hline 17 & 36.3185 & 36.904 & 37.1120 \\
\hline 18 & 35.964 & 36.3797 & 36.8880 \\
\hline 19 & 34.8113 & 35.0571 & 35.9008 \\
\hline 20 & 32.8611 & 32.9368 & 34.1827 \\
\hline 21 & 38.0964 & 39.7377 & 39.0903 \\
\hline 22 & 42.534 & 44.003 & 43.3754 \\
\hline 23 & 46.1732 & 47.4709 & 46.8883 \\
\hline 24 & 49.0138 & 50.1406 & 49.6838 \\
\hline 25 & 51.0557 & 52.012 & 51.6917 \\
\hline 26 & 52.2988 & 53.0849 & 52.9865 \\
\hline 27 & 52.7432 & 53.3593 & 53.5019 \\
\hline 28 & 52.3892 & 52.8353 & 53.2430 \\
\hline 29 & 51.237 & 51.513 & 52.2814 \\
\hline 30 & 49.287 & 49.3929 & 50.5515 \\
\hline
\end{tabular}

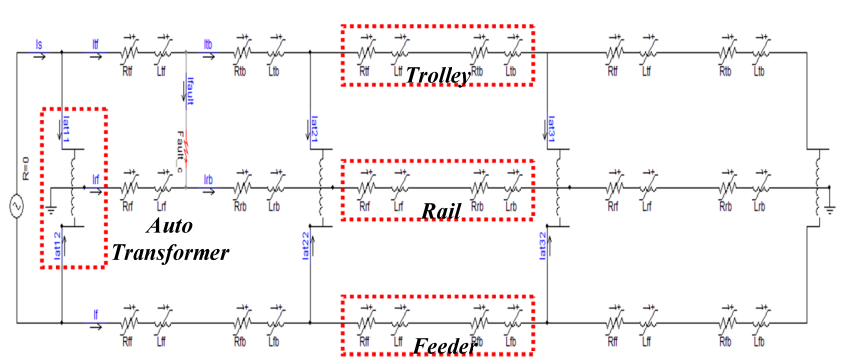

Fig. 6. AT feeder system modeling of AC electric railway (The 1st Section)

The scott transformer secondary voltage is $55[\mathrm{kV}]$ and modelling is made in the order of SS-SSP-SP. The primary winding is connected to twice times the number of turns of the secondary side in auto-transformer (AT). The voltage on the primary side is $55[\mathrm{kV}]$, Voltage on the secondary side is 27.5 [kV]. The point connecting both windings is connected to the rail.

The short circuit fault is simulated at each $1[\mathrm{~km}]$ interval in a section of 1 30 [km]. Fig. 7 shows an example of short circuit fault, and shows the (a) instantaneous value and the (b) RMS current value. Comparison of numerical analysis
Table 4. Comparison of conventional calculation and simulation value for short-circuit current

\begin{tabular}{|c|c|c|c|}
\hline \multirow[b]{2}{*}{$\begin{array}{c}\text { Distance } \\
{[\mathrm{km}]}\end{array}$} & \multicolumn{2}{|c|}{ Short-circuit current[A] } & \multirow[b]{2}{*}{$\begin{array}{c}\text { Error rate } \\
{[\%]}\end{array}$} \\
\hline & $\begin{array}{c}\text { Conventional } \\
\text { calculation data }\end{array}$ & $\begin{array}{c}\text { Simulation } \\
\text { data }\end{array}$ & \\
\hline 1 & 10476 & 10196 & $2.676 \%$ \\
\hline 2 & 5676 & 5606 & $1.240 \%$ \\
\hline 3 & 4126 & 4094 & $0.782 \%$ \\
\hline 4 & 3401 & 3382 & $0.570 \%$ \\
\hline 5 & 3020 & 3006 & $0.469 \%$ \\
\hline 6 & 2827 & 2815 & $0.436 \%$ \\
\hline 7 & 2764 & 2752 & $0.448 \%$ \\
\hline 8 & 2815 & 2800 & $0.523 \%$ \\
\hline 9 & 2991 & 2972 & $0.648 \%$ \\
\hline 10 & 3346 & 3317 & $0.881 \%$ \\
\hline 11 & 2538 & 2525 & $0.509 \%$ \\
\hline 12 & 2107 & 2100 & $0.310 \%$ \\
\hline 13 & 1849 & 1845 & $0.205 \%$ \\
\hline 14 & 1688 & 1686 & $0.097 \%$ \\
\hline 15 & 1588 & 1587 & $0.072 \%$ \\
\hline 16 & 1533 & 1532 & $0.073 \%$ \\
\hline 17 & 1514 & 1513 & $0.091 \%$ \\
\hline 18 & 1529 & 1528 & $0.085 \%$ \\
\hline 19 & 1580 & 1578 & $0.123 \%$ \\
\hline 20 & 1674 & 1671 & $0.162 \%$ \\
\hline 21 & 1444 & 1441 & $0.187 \%$ \\
\hline 22 & 1293 & 1292 & $0.084 \%$ \\
\hline 23 & 1191 & 1191 & $0.014 \%$ \\
\hline 24 & 1122 & 1122 & $0.012 \%$ \\
\hline 25 & 1077 & 1078 & $0.069 \%$ \\
\hline 26 & 1052 & 1052 & $0.033 \%$ \\
\hline 27 & 1043 & 1043 & $0.020 \%$ \\
\hline 28 & 1050 & 1050 & $0.016 \%$ \\
\hline 29 & 1073 & 1074 & $0.052 \%$ \\
\hline 30 & 1116 & 1116 & $0.008 \%$ \\
\hline \multicolumn{3}{|c|}{ Average error rate } & $0.363 \%$ \\
\hline
\end{tabular}

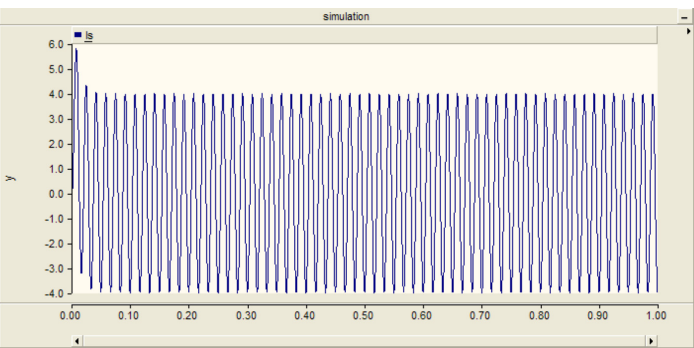

(a) $6[\mathrm{~km}]$ point short circuit fault instantaneous current (X axis : [sec]., Y axis : [kA])

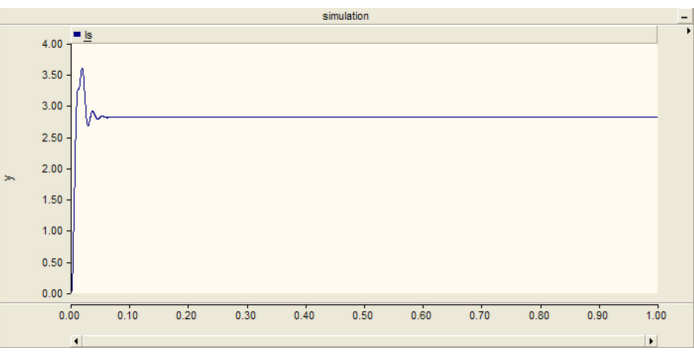

(b) $6[\mathrm{~km}]$ point short circuit fault RMS current (X axis : [sec]., Y axis : [kA])

Fig. 7. $6[\mathrm{~km}]$ point short circuit fault current waveform 
and simulation result was done in a steady-state of the RMS values.

\subsubsection{Simulation of conventional calculation method $\left(Z_{A T}=0.033 j[\Omega]\right)$}

The leakage reactance is applied to confirm the effect of leakage reactance in the simulation. First, the leakage reactance is set to a very small value in order to analyze the values of the condition without leakage reactance of auto-transformer in 2.5.2, and the simulation was carried out. Table 4 shows comparison of simulation results and short-circuit current value using conventional numerical calculation. And the maximum error rate in the section 1 is $2.676[\%]$ of $1[\mathrm{~km}]$ point, and the minimum error rate is $0.008[\%]$ of $30[\mathrm{~km}]$ points. The result is less than $1[\%]$ excepting at point $1[\mathrm{~km}]$ and $2[\mathrm{~km}]$. Because the shortcircuit current of $1,2[\mathrm{~km}]$ is larger than the short-circuit current of the other point, the error rate is increased. The short circuit current value and the value of the numerical simulation calculations were almost similar as the average error rate was $0.363[\%]$.

Table 5. Comparison of proposed calculation and simulation value for short-circuit current

\begin{tabular}{|c|c|c|c|}
\hline \multirow{2}{*}{$\begin{array}{c}\text { Distance } \\
{[\mathrm{km}]}\end{array}$} & \multicolumn{2}{|c|}{ Short-circuit current[A] } & \multirow{2}{*}{$\begin{array}{c}\text { Error rate } \\
{[\%]}\end{array}$} \\
\hline & $\begin{array}{c}\text { Proposed } \\
\text { calculation data }\end{array}$ & $\begin{array}{c}\text { Simulation } \\
\text { data }\end{array}$ & \\
\hline 1 & 10363 & 10196 & $1.641 \%$ \\
\hline 2 & 5647 & 5606 & $0.724 \%$ \\
\hline 3 & 4112 & 4094 & $0.449 \%$ \\
\hline 4 & 3393 & 3382 & $0.333 \%$ \\
\hline 5 & 3015 & 3006 & $0.291 \%$ \\
\hline 6 & 2823 & 2815 & $0.301 \%$ \\
\hline 7 & 2762 & 2752 & $0.348 \%$ \\
\hline 8 & 2813 & 2800 & $0.453 \%$ \\
\hline 9 & 2990 & 2972 & $0.609 \%$ \\
\hline 10 & 3346 & 3317 & $0.879 \%$ \\
\hline 11 & 2528 & 2525 & $0.107 \%$ \\
\hline 12 & 2100 & 2100 & $0.000 \%$ \\
\hline 13 & 1844 & 1845 & $0.046 \%$ \\
\hline 14 & 1684 & 1686 & $0.113 \%$ \\
\hline 15 & 1585 & 1587 & $0.108 \%$ \\
\hline 16 & 1531 & 1532 & $0.083 \%$ \\
\hline 17 & 1512 & 1513 & $0.047 \%$ \\
\hline 18 & 1527 & 1528 & $0.037 \%$ \\
\hline 19 & 1578 & 1578 & $0.014 \%$ \\
\hline 20 & 1672 & 1671 & $0.065 \%$ \\
\hline 21 & 1439 & 1441 & $0.121 \%$ \\
\hline 22 & 1290 & 1292 & $0.178 \%$ \\
\hline 23 & 1188 & 1191 & $0.213 \%$ \\
\hline 24 & 1120 & 1122 & $0.189 \%$ \\
\hline 25 & 1075 & 1078 & $0.250 \%$ \\
\hline 26 & 1050 & 1052 & $0.198 \%$ \\
\hline 27 & 1041 & 1043 & $0.172 \%$ \\
\hline 28 & 1048 & 1050 & $0.157 \%$ \\
\hline 29 & 1072 & 1074 & $0.184 \%$ \\
\hline 30 & 1115 & 1116 & $0.133 \%$ \\
\hline \multicolumn{3}{|c|}{ Average error rate } & $0.281 \%$ \\
\hline
\end{tabular}

\subsubsection{Simulation of proposed calculation method $\left(Z_{A T}=\right.$ $0.033 j[\Omega])$}

Table 5 shows comparison of the simulation results and short-circuit current value using the proposed numerical calculation and the maximum error rate in section 1 is $1.641[\%]$ of $1[\mathrm{~km}]$ point like the conventional calculation method, and minimum error rate is $0[\%]$ over $12[\mathrm{~km}]$ point and the result is less than $1[\%]$ except points $1[\mathrm{~km}]$.

The proposed formula is simpler but the results were more accurate as the average error rate is 0.281 [\%].

\subsubsection{Simulation of conventional calculation method $\left(Z_{A T}=0.45 j[\Omega]\right)$}

The leakage impedance of the actual auto-transformer is applied in the simulation. Table 6 is tables comparing the simulation results with short-circuit current value using conventional numerical calculation and the maximum error rate in the section 1 is 25.299 [\%] of $1[\mathrm{~km}]$ point, and the minimum error rate is $1.23[\%]$ of $25[\mathrm{~km}]$ points. The average error rate was $4.624[\%]$.

Table 6. Comparison of conventional calculation and simulation value for short-circuit current

\begin{tabular}{|c|c|c|c|}
\hline \multirow{2}{*}{$\begin{array}{c}\text { Distance } \\
{[\mathrm{km}]}\end{array}$} & \multicolumn{2}{|c|}{ Short-circuit current[A] } & \multirow{2}{*}{$\begin{array}{c}\text { Error rate } \\
{[\%]}\end{array}$} \\
\hline & $\begin{array}{c}\text { Conventional } \\
\text { calculation data }\end{array}$ & $\begin{array}{c}\text { Simulation } \\
\text { data }\end{array}$ & \\
\hline 1 & 10476 & 7826 & $25.299 \%$ \\
\hline 2 & 5676 & 4908 & $13.536 \%$ \\
\hline 3 & 4126 & 3754 & $9.022 \%$ \\
\hline 4 & 3401 & 3169 & $6.833 \%$ \\
\hline 5 & 3020 & 2847 & $5.733 \%$ \\
\hline 6 & 2827 & 2677 & $5.317 \%$ \\
\hline 7 & 2764 & 2615 & $5.404 \%$ \\
\hline 8 & 2815 & 2647 & $5.958 \%$ \\
\hline 9 & 2991 & 2779 & $7.100 \%$ \\
\hline 10 & 3346 & 3044 & $9.039 \%$ \\
\hline 11 & 2538 & 2420 & $4.647 \%$ \\
\hline 12 & 2107 & 2037 & $3.300 \%$ \\
\hline 13 & 1849 & 1802 & $2.531 \%$ \\
\hline 14 & 1688 & 1652 & $2.112 \%$ \\
\hline 15 & 1588 & 1557 & $1.961 \%$ \\
\hline 16 & 1533 & 1503 & $1.965 \%$ \\
\hline 17 & 1514 & 1482 & $2.138 \%$ \\
\hline 18 & 1529 & 1491 & $2.505 \%$ \\
\hline 19 & 1580 & 1532 & $3.035 \%$ \\
\hline 20 & 1674 & 1609 & $3.866 \%$ \\
\hline 21 & 1444 & 1407 & $2.542 \%$ \\
\hline 22 & 1293 & 1268 & $1.940 \%$ \\
\hline 23 & 1191 & 1173 & $1.525 \%$ \\
\hline 24 & 1122 & 1107 & $1.349 \%$ \\
\hline 25 & 1077 & 1064 & $1.230 \%$ \\
\hline 26 & 1052 & 1038 & $1.298 \%$ \\
\hline 27 & 1043 & 1028 & $1.418 \%$ \\
\hline 28 & 1050 & 1033 & $1.604 \%$ \\
\hline 29 & 1073 & 1052 & $1.998 \%$ \\
\hline 30 & 1116 & 1088 & $2.501 \%$ \\
\hline \multicolumn{3}{|c|}{ Average error rate } & $4.624 \%$ \\
\hline
\end{tabular}


Table 7. Comparison of proposed calculation and simulation value for short-circuit current

\begin{tabular}{|c|c|c|c|}
\hline \multirow{2}{*}{$\begin{array}{c}\text { Distance } \\
{[\mathrm{km}]}\end{array}$} & \multicolumn{2}{|c|}{ Short-circuit current[A] } & \multirow{2}{*}{$\begin{array}{c}\text { Error rate } \\
{[\%]}\end{array}$} \\
\hline & $\begin{array}{c}\text { Proposed calculation } \\
\text { data }\end{array}$ & $\begin{array}{c}\text { Simulation } \\
\text { data }\end{array}$ & \\
\hline 1 & 8057 & 7826 & $2.869 \%$ \\
\hline 2 & 4959 & 4908 & $1.026 \%$ \\
\hline 3 & 3777 & 3754 & $0.619 \%$ \\
\hline 4 & 3192 & 3169 & $0.717 \%$ \\
\hline 5 & 2879 & 2847 & $1.115 \%$ \\
\hline 6 & 2726 & 2677 & $1.797 \%$ \\
\hline 7 & 2689 & 2615 & $2.770 \%$ \\
\hline 8 & 2760 & 2647 & $4.106 \%$ \\
\hline 9 & 2957 & 2779 & $6.011 \%$ \\
\hline 10 & 3337 & 3044 & $8.787 \%$ \\
\hline 11 & 2362 & 2420 & $2.439 \%$ \\
\hline 12 & 1997 & 2037 & $2.024 \%$ \\
\hline 13 & 1773 & 1802 & $1.617 \%$ \\
\hline 14 & 1633 & 1652 & $1.178 \%$ \\
\hline 15 & 1547 & 1557 & $0.658 \%$ \\
\hline 16 & 1502 & 1503 & $0.099 \%$ \\
\hline 17 & 1490 & 1482 & $0.560 \%$ \\
\hline 18 & 1512 & 1491 & $1.378 \%$ \\
\hline 19 & 1569 & 1532 & $2.350 \%$ \\
\hline 20 & 1670 & 1609 & $3.645 \%$ \\
\hline 21 & 1384 & 1407 & $1.656 \%$ \\
\hline 22 & 1250 & 1268 & $1.447 \%$ \\
\hline 23 & 1159 & 1173 & $1.242 \%$ \\
\hline 24 & 1097 & 1107 & $0.919 \%$ \\
\hline 25 & 1057 & 1064 & $0.620 \%$ \\
\hline 26 & 1036 & 1038 & $0.186 \%$ \\
\hline 27 & 1031 & 1028 & $0.267 \%$ \\
\hline 28 & 1041 & 1033 & $0.766 \%$ \\
\hline 29 & 1068 & 1052 & $1.470 \%$ \\
\hline 30 & 1114 & 1088 & $2.292 \%$ \\
\hline \multicolumn{3}{|c|}{ Average error rate } & $1.888 \%$ \\
\hline
\end{tabular}

\subsubsection{Simulation of proposed calculation method $\left(Z_{A T}=\right.$ $0.45 j[\Omega])$}

Table 7 is tables comparing the simulation results with short-circuit current value using the proposed numerical calculation and the maximum error rate in section 1 is $8.787[\%]$ of $10[\mathrm{~km}]$ point and minimum error rate is 0.099 [\%] over $16[\mathrm{~km}]$ points.

The proposed formula is simpler but the results were more accurate as the average error rate is 1.888 [\%].

\subsection{Comparing the error rate on the basis of simulation}

Fig. 8 is a compares the proposed and conventional error rate calculation method. In section 1 , error rates are the same. but error rate of the proposed calculation method is lower except after $23[\mathrm{Km}]$ and It can be confirmed that the proposed calculation method is lower by as much as 0.006 [\%].

Fig. 9 shows comparison of the proposed and conventional error rate calculation method when applying the leakage reactance. Error rate of the proposed calculation

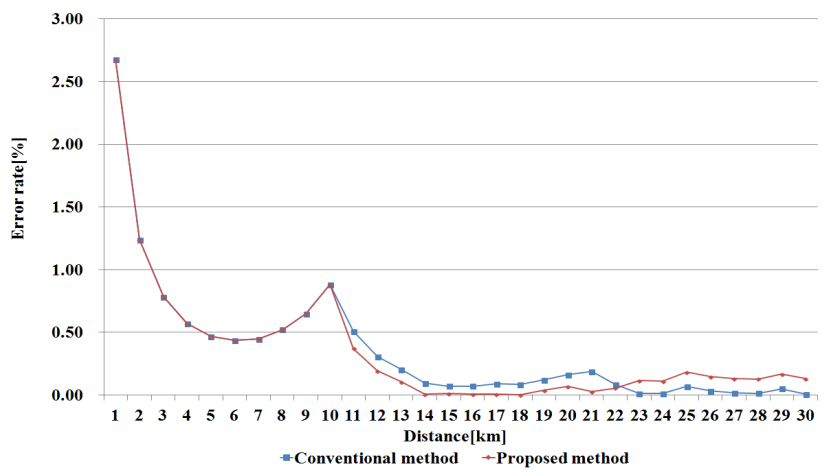

Fig. 8. Comparison of error $\operatorname{rate}\left(Z_{A T}=0.033 \mathrm{j}[\Omega]\right)$

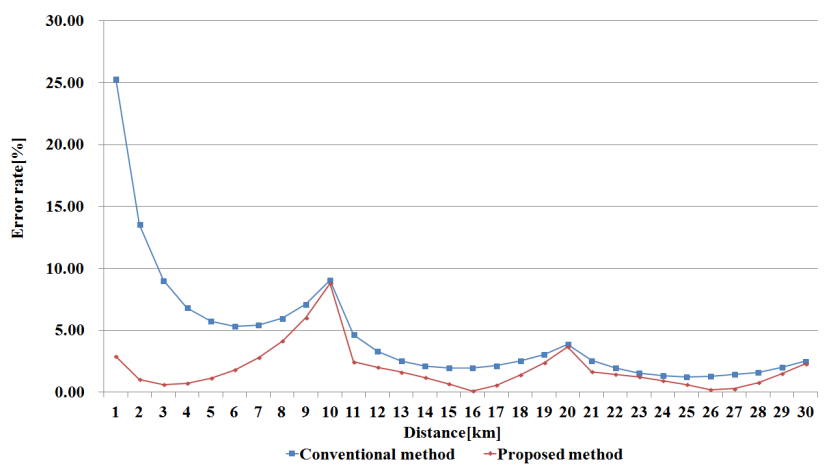

Fig. 9. Comparison of error $\operatorname{rate}\left(Z_{A T}=0.45 \mathrm{j}[\Omega]\right)$

method is lower and It can be confirmed that the proposed calculation method is lower by as much as 2.836 [\%].

\section{Conclusion}

In this paper, short-circuit current is analyzed by numerical analysis and simulation for the correct operation of the protective relay and the formula has been proposed for simple and accurate calculation of the short-circuit current.

In order to confirm the validity of the proposed formula, the simulation error rate was analyzed compared with the conventional numerical methods.

The average error rate of comparing the short circuit current value using conventional calculation method and the value of the numerical simulation calculations was $0.363[\%]$; and the average error rate of comparing the short circuit current value using proposed calculation method with the value of the numerical simulation calculations was $0.357[\%]$. These results were similar but the error rate of the proposed calculation method is lower than the conventional one.

Compared to simulation applying the leakage reactance of the actual auto-transformer, error rate of the conventional method is $4.624 \%$ and error rate of the proposed method is $1.888 \%$. It can be confirmed that the proposed calculation method is lower by as much as 2.836 [\%]. It is considered 
an error because the simulation results are not correct to $100 \%$. Thus, it demonstrated the feasibility of the proposed calculation method.

In future research, the study to increase the accuracy of the protection relays is required taking into consideration the source impedance.

\section{References}

[1] Sung IL Kwon et al, Development of Integrated Protection Relay for AC Railway System with Time Synchronization Function: R\&D Plan Report, 2014.7

[2] Park, Byoung Bae, A Comparative Study on Feeder Protective Relay Systems for AC Electrified Railway: Master's thesis, Seoultech, 2010.2

[3] Korail, A Study of the Catenary Circuit Constant Measurement and Protection Circuit Optimization: 1998

[4] Lee, Hee Yong, A study on Railway Electric Traction Protection System: Master's thesis, Seoultech, 2005.2

[5] Hanmin Lee et al, Fault Analysis of AC Electric Railway System Mode by EMTDC: 2003

[6] Hanmin Lee et al, Comparison of AC Electric Railway System Model using the EMTDC, 2003

[7] Hanmin Lee et al, Modelling AC Electric Railway System using the PSCAO/EMTDC, 2002

[8] Yang Su Kim et al, Wonju $\sim$ Gangneung AC Feeder Simulation Report: 2014

[9] Choe, Seung Hyuk, Influence of the AT(AutoTransformer) in ATP(Auto-Transformer Post) to the AC Electric Railway system: Master's thesis, Seoultech, 2011

[10] No-Geon Jung, The Comparative Analysis of Fault Current using EMTDC and Numerical Computation of AT Feeding System, 2015

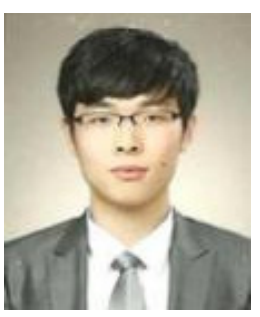

No-Geon Jung received the B.S. degree in rolling stocks electric engineering from the Korea National Railroad College, Korea, in 2012, and then received M.S. degree from Korea National University of Transportation in 2015, Since 2015, he has been with Korea National University of Transportation, where he is currently a Ph.D. course. His research interest is power electronics of railway.

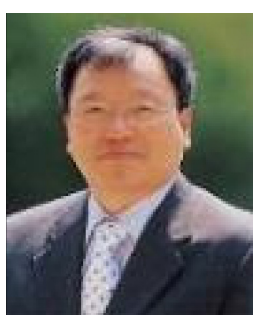

Ki-Sik Lee received the B.S., M.S. and $\mathrm{Ph} . \mathrm{D}$. degrees in electrical engineering from the Seoul University, Korea, in 1973, 1977 and 1985, respectively. Since 1978, he has been with Dankook University, Korea, is now a Professor in electrical engineering. His research interest is electrical engineering. 